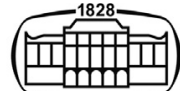

AKADÉMIAI KIADÓ

UNIVERSITY of DEBRECEN

International Review of Applied Sciences and Engineering

$12(2021) 3,222-229$

DOI:

$10.1556 / 1848.2021 .00236$

(c) 2021 The Author(s)

ORIGINAL RESEARCH PAPER

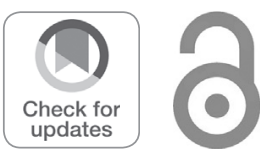

\section{The shear resistance of a member without shear reinforcement according to Eurocode 2; the error of the calculated value and the mechanical explanation of the problem}

\author{
Béla Bogdándy* ๑
}

Department of Architecture, Faculty of Engineering, University of Debrecen, H-4028, Otemetö u. 2-4., Debrecen, Hungary

Received: January 4, 2021 - Accepted: May 3, 2021

Published online: June 29, 2021

\section{ABSTRACT}

In this paper the shear resistance of a member without shear reinforcement according to Eurocode 2 is investigated. This expression, as most expressions of design codes typically used to estimate the nominal shear resistance, has been created based on experimental investigations. It will be verified that in case of non-prestressed reinforced concrete member without stirrups, the shear resistance is carried by the shear resistance of the compressive zone; and the shear resistance given by the empirical expression of Eurocode 2 is actually the shear resistance of the compressive zone.

Knowing the mechanical background of the empirical expressions of Eurocode 2, the limits of its applicability can be shown, thus its error can be predicted. Using the reports of experimental investigations, it is easy to find cases to prove the correctness of the error-prediction. In this paper simple modifications will be suggested to Eurocode 2 shear design procedures, by which a more consistent level of safety can be ensured.

\section{KEYWORDS}

reinforced concrete beams, shear, shear strength, Eurocode 2

\section{INTRODUCTION}

As in most design codes, in cases where members do not require design shear reinforcement, the expression of the design value for the shear resistance given by Eurocode 2 is based on experimental investigations. Although the expression according to Eurocode 2 is the result of many decades of extensive research, in the absence of a mechanical background of the empirical expression it may contain hidden error, since the experiments obviously cannot cover all possible design situations.

After developing a simple shear failure model, the mechanical background of the empirical expressions of Eurocode 2 and the limits of its applicability can be shown. The model predicts the error of the empirical expression according to Eurocode 2, thus it is easy to find cases that prove the correctness of the model amongst the several experimental results.

Knowing the mechanical background of the empirical expressions of Eurocode, the error can be predicted and easily corrected.

\section{BEHAVIOUR OF BEAMS WITHOUT SHEAR REINFORCEMENT}

A beam resists loads primarily by means of internal moments and shears. In the design procedure of a reinforced concrete usually member flexure is considered first, from which the size of the cross-section and the arrangement of reinforcement can be determined to provide the 
necessary moment resistance. After that, knowing the amount of longitudinal reinforcement, the beam is designed for shear. Since the shear failure is brittle and sudden, the design for shear must ensure that the shear resistance is equal to or greater than the flexural resistance at all points in the beam [1].

In those cases where a beam does not contain shear reinforcement it will fail when the inclined crack occurs. At the moment of cracking the shear resistance of the member is equal to the inclined cracking load. The inclined cracking load of a beam is mainly affected by the tensile strength of concrete, the longitudinal reinforcement ratio, the shear span-to-depth ratio, the size of beam and the maximum aggregate size.

The inclined cracking load is very closely related to the tensile strength of concrete. The analysis of stresses showed that the biaxial stress state in the web of the beam is similar to the biaxial stress state which exists in a split-cylinder tension test [2]. Since the flexural cracking precedes the inclined cracking and disrupts the elastic-stress field, the relationship between two quantities is not straightforward.

The longitudinal reinforcement ratio, similarly to the tensile strength of concrete, is also related to the inclined cracking load [3]. In case when the longitudinal reinforcement ratio is low, flexural cracks open wider. This increase in crack width causes a decrease in the values of the components of shear resistance, which are transferred across the inclined cracks.

The effect of the shear span-to-depth ratio is only significant in case of deep beams. For slender beams, where the shear span is long, this ratio has very little effect on the shear resistance, therefore, it can be neglected [4].

Research in recent decades has shown that there is a close link between the shear resistance and the size of beam [5]. The effect of beam size on shear resistance has not been clarified in detail. In design codes this effect is taken into account by the size effect factor, which is based on experimental investigations. It should be noted that using fracture mechanics, the size effect can be explained by the energy release on cracking [6].

The effect of the maximum aggregate size on shear resistance is based on the fact that, as the size of the aggregate increases, the roughness of the crack surface increases. Due to the increase of the roughness of the crack surface, higher shear stresses can be transferred across the cracks, increasing the shear transferred by aggregate interlock [7]. However, in high-strength concrete beams the cracks pass through the aggregate rather than going around them, thus the crack surface becomes smoother, which implies a decrease in the shear transferred by aggregate interlock [8].

\section{THE SHEAR RESISTANCE OF A MEMBER WITHOUT SHEAR REINFORCEMENT ACCORDING TO EUROCODE 2}

The design model for the shear resistance without shear reinforcement according to Eurocode 2 [9] considers a shear strength which depends on the concrete cylinder strength, the flexural reinforcement ratio and the size effect factor.

In case when there is no axial force in the cross-section due to loading or prestressing, the design value for the shear resistance is given by:

$$
V_{R d, c}=\frac{0.18}{\gamma_{c}} k\left(100 \rho_{l} f_{c k}\right)^{1 / 3} b_{w} d
$$

with a minimum of

$$
V_{R d, c}=v_{\min } b_{w} d
$$

where $\gamma_{c}$ is the partial factor for concrete, $k$ is the size effect factor, $\rho_{l}$ is the reinforcement ratio for longitudinal reinforcement, $f_{c k}$ is the characteristic compressive cylinder strength of concrete in $\mathrm{MPa}, b_{w}$ is the width of the web, $d$ is the effective depth of the cross-section, and $v_{\text {min }}=0.035 k^{3 / 2}$ $f_{c k}{ }^{1 / 2}$. The factor $k$ can be determined by

$$
k=1+\sqrt{\frac{200}{d} \leq 2.0}, \text { where } d \text { in } \mathrm{mm} .
$$

We have to recognize that Eq. (1) can be written as

$$
V_{R d, c}=v_{R d, c} b_{w} d
$$

where $v_{R d, c}$ is the design value of shear strength of a reinforced concrete cross-section in MPa. The value of $v_{R c}=\gamma_{c}$ $v_{R d, c}$ is empirically derived from test results by that the measured shear force at failure divided by the value of $b_{w} d$. It should be noted that this shear strength is related to the reinforced concrete cross-section, thus it does not match the shear strength of concrete.

\section{THE SHEAR STRENGTH OF A REINFORCED CONCRETE MEMBER}

\subsection{Derivation of shear strength}

In the first step to derive the shear strength, let us examine the forces transferring shear across an inclined crack in a beam without stirrups (see in Fig. 1).

Vertical force equilibrium shows that shear is transferred by $V_{c}$, the shear in compression zone, by $A_{y}$, the vertical component of the shear transferred across the crack by interlock of the aggregate particles on the two faces of the crack, and by $V_{D}$, the dowel action of the longitudinal reinforcement. Thus the shear resistance of a beam without shear reinforcement is $V_{R c}=V_{c}+A_{y}+V_{D}$, where $V_{R c}$ is
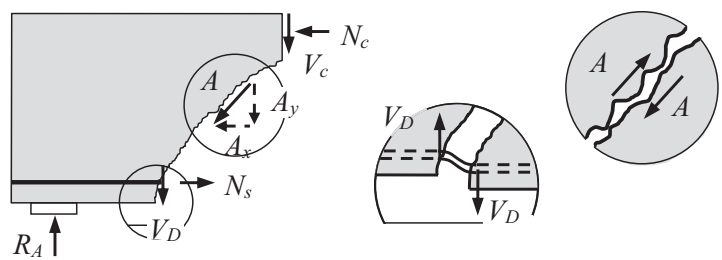

Fig. 1. Internal forces in a cracked beam without shear reinforcement [1] 
referred to somewhat incorrectly and misleadingly as "the shear carried by the concrete" [10]. The shear failure of a slender beam without stirrups is sudden and dramatic.

Nevertheless, it seems obvious that the value of $V_{R c}=V_{c}$ $+A_{y}+V_{D}$ has to correspond with the characteristic value of Eq. (1), which can be written as

$$
V_{R c}=\gamma_{c} V_{R d, c}=0,18 k\left(100 \rho_{l} f_{c k}\right)^{1 / 3} b_{w} d
$$

In the following, we assume that the shear resistance of a beam without stirrups is well characterized by the shear resistance of compression zone, $V_{c}$, thus $V_{R c}$ in Eq. (4) is equal to $V_{c}$. This assumption seems somewhat arbitrary, but as the shear force grows the shear crack widens, $A_{y}$ decreases and due to splitting cracks in the concrete along the reinforcement, $V_{D}$ drops, approaching zero. When $A_{y}$ and $V_{D}$ disappear shear is transmitted only by the compression zone [1]. The correctness of this assumption has also been shown in a recent study [11].

As a simplification, further investigations are related to a rectangular cross-section, thus $b_{w}=b$, where $b$ is the width of the cross-section.

\subsection{The shear resistance of the compression zone}

To calculate the shear resistance of the compression zone, first we need to know the distributions of stresses of the compression zone, and after that we need to define the failure criterion of the biaxial stress state. These investigations assume that neither the steel nor the concrete will reach its respective capacity, thus their behaviour is characterized by linear stress-strain relationship which is also referred to as cracked-elastic behaviour.

To obtain the shear stress distribution in the compression zone, the equilibrium of the part of the cross-section above the cracked region was investigated. This analysis showed that the shear stress distribution depends only on the change of moment, $\Delta M$, along $d x$, and it remains parabolic as long as the change of flexural stresses caused by $\Delta M$ could be considered linear (see in detail [12]).

The maximum shear stress is given by

$$
\tau_{\max }=\frac{3}{2} \frac{V}{b x_{I I}}
$$

where $V$ is the shear force on the cross-section and $x_{I I}$ is the depth of the compression zone calculated by assuming cracked-elastic behaviour. For the special case of rectangular beams without compression reinforcement, the value of $x_{I I}$ is given by

$$
x_{I I}=\xi_{I I} d
$$

where

$$
\xi_{I I}=x_{I I} / d=\sqrt{2 \rho_{l} n+\left(\rho_{l} n\right)^{2}}-\rho_{l} n
$$

in which $n=E_{s} / E_{c m}$ is the modular ratio and $\rho_{l}=A_{s} / b d$.

The cracked beam, the portion of beam between two cracks, and the shear stress distribution in the cracked region are shown in Fig. 2. This figure also shows the average
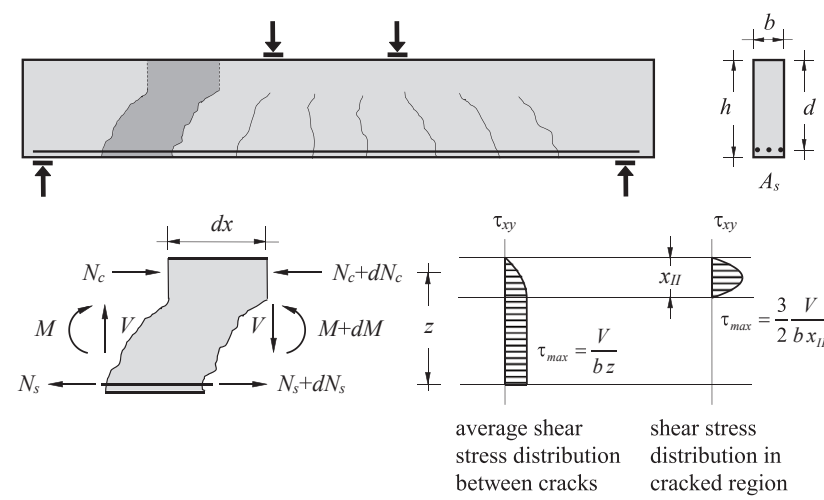

Fig. 2. Cracked beam, portion of beam between two cracks and shear stress distributions

shear stress distribution between two cracks. It should be noted that this average distribution is the basis of design procedure for most design standards [1].

The next step in the determination of the shear resistance of the compression zone is to define the failure criterion of the biaxial stress state, $\tau=f(\sigma)$. Due to the elastico-viscous behaviour of the concrete, the failure criterion can be defined by the Mohr-Coulomb theory.

Mohr's circles for uniaxial compression and tension, the Coulomb line and second-order polynomial Mohr's envelope are shown in Fig. 3. This figure also shows the failure criterions of biaxial stresses derived from the Coulomb line, $\tau(\sigma)_{M O H R}$, and the second-order polynomial Mohr's envelope, $\tau(\sigma)_{W A L T H E R}[13]$.

In fact, the failure criterion called $\tau(\sigma)_{M O H R}$ is an equation of an ellipse and the maximum of the function is

$$
\tau(\sigma)_{M O H R, \max }=\tau_{c, M O H R}=0,5 \sqrt{f_{c} f_{c t}},
$$

which value matches the ultimate shear strength of concrete given by Mohr. The various failure criterions shown in Fig. 3 can be defined by the following functions:

$$
\begin{gathered}
\tau(\sigma)_{M O H R}=\sqrt{\frac{f_{c} f_{c t}\left(f_{c}-\sigma\right)\left(f_{c t}+\sigma\right)}{\left(f_{c}+f_{c t}\right)^{2}}}, \\
\tau(\sigma)_{\text {WALTHER }}=\frac{1}{2} \sqrt{f_{c} \sigma-\sigma^{2}} \text { if } \sigma>f_{c} / 4 \text {, or }
\end{gathered}
$$

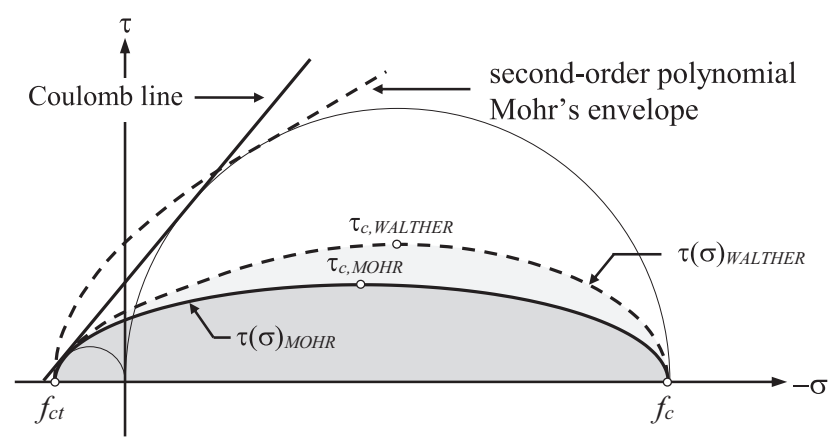

Fig. 3. Various failure criterions of the compression zone 


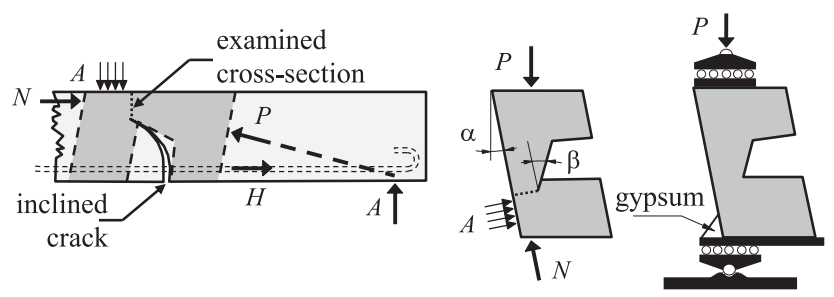

Fig. 4. Kármán's experimental layout and test specimens

$$
\tau(\sigma)_{\text {WALTHER }}=\frac{f_{c}}{8} \sqrt{1+\frac{8 \sigma}{f_{c}}} \text { if } \sigma<f_{c} / 4, \text { and } f_{c t}=f_{c} / 8,
$$

where $f_{c t}$ is the tensile strength and $f_{c}$ is the compressive strength of concrete. As shown in Fig. 3, from the various failure criterions different ultimate shear strength of concrete, $\tau_{c}=\tau(\sigma)_{\max }$, can be calculated. The difference is significant, for $f_{c t}=f_{c} / 8$ can be computed as $\tau_{c, \text { WALTHER }}=$ $1.41 \tau_{c, M O H R}$. In the literature for shear strength of concrete, $\tau_{c}$, values can be found in the range of $\tau_{c}=1.00 \ldots 2.00$ $\tau_{c, M O H R}$.

To select the appropriate failure criterion, experimental results reported by Kármán [14] were used. In Kármán's experimental investigation the resistance of the compression zone was examined by special test specimens. The experimental layout and test specimens are shown in Fig. 4.

The experimental results reported by Kármán are shown in Fig. 5. This figure also shows the failure criterion based on experimental results, $\tau(\sigma)_{\text {exp. }}$, and Mohr's failure criterion, $\tau(\sigma)_{M O H R}$. During this investigation the cubic compressive strength of concrete was $K=f_{c, c u b e, 200}=56 \mathrm{MPa}$ from which $f_{c m}=f_{c, c y l}=0.873 f_{c, c u b e, 200}=56 \mathrm{MPa}$ and $f_{c t m}=0.3 f_{c k}{ }^{2 / 3}$ $=3.57 \mathrm{MPa}$ can be calculated according to [15] and [9], respectively. Having $f_{c m}$ and $f_{c t m}$, by using Eq. (8) the value for shear strength of concrete according to Mohr can be computed, we obtain $\tau_{c, M O H R}=6.66 \mathrm{MPa}$.

The experimental failure criterion, $\tau(\sigma)_{\text {exp. }}$, was computed by the method of least squares and the regression curve was assumed as an ellipse similarly to Mohr's failure criterion. Thus, the function of $\tau(\sigma)_{\exp }$. corresponds as a mean value, from which the mean value of shear strength of concrete is $\tau(\sigma)_{\text {exp.,max }}=\tau_{c, m}=9.58 \mathrm{MPa}$.

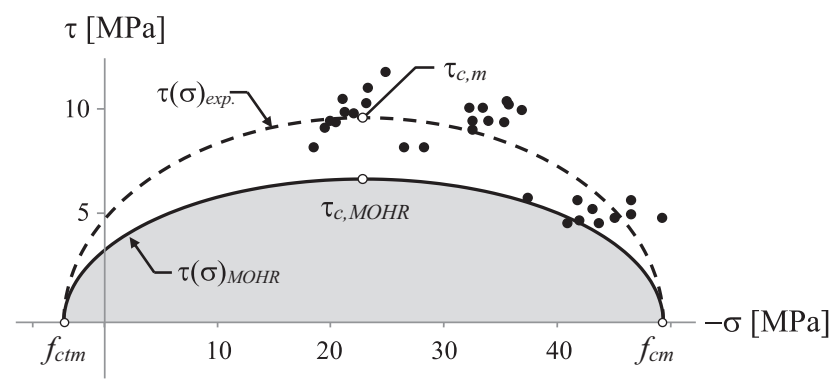

Fig. 5. Experimental results reported by Kármán with the experimental and the Mohr's failure criterion
If $\tau_{c, m}$ is a mean value and it follows a standard statistical distribution, then the characteristic value, $\tau_{c, k}$, should be defined as the $5 \%$ fractile value. Therefore, the characteristic value for the shear strength of concrete is

$$
\tau_{c, k}=\tau_{c, m}-t s
$$

where $t$ is the value of Student's $t$-distribution and $s$ is the sample standard deviation. For sample $34, t=1,685$ and from the test results $s=1,571$ can be calculated. If these values are substituted into Eq. (10), then the result is $\tau_{c, k}=$ 6.93 $\mathrm{MPa}$. Thus, the value of $\tau_{c, k}$ is practically the same as the value of $\tau_{c, M O H R}$, the calculated error is less than 5 percent, so it can be finally concluded that, by substituting $f_{c}=f_{c m}$ and $f_{c t}=f_{c t m}$ in Eq. (8), the value of $\tau_{c, M O H R}$ is the characteristic value for shear strength of concrete.

Now, knowing the distributions of stresses of the compression zone and the failure criterion of the biaxial stress state, the shear resistance of the compressive zone can be calculated. In this case, the shear resistance becomes a function of the curvature of the cross-section.

An analytically created moment-curvature and shear resistance-curvature relationships are shown in Fig. 6. In calculations a simple elastic - perfectly plastic model was assumed for the reinforcing steel in tension, with the steel elastic modulus $E_{s}=200 \mathrm{GPa}$. For concrete in compression zone, the non-linear stress-strain relationship according to Eurocode 2 was assumed. During the calculations the tensile strength of concrete was neglected, and thus, the momentcurvature curve does not show the uncracked-elastic range of behaviour. For comparison of the calculated predictions with experimental results, test data reported by Leonhardt and Walther [16] also plotted in Fig. 6. This figure shows those test results, next to the shear resistance according to Eurocode 2, where the shear span-to-depth ratio, $a / d$, was from 2.5 to 6 .

As shown in Fig. 6, the shear resistance of a member without shear reinforcement can be well characterized by the shear resistance of the compressive zone. It should be noted that Tureyen and Frosch reached a similar conclusion in [17]. In case when $a / d$ is less than 2.5 the shear resistance is increased due to the arch action, thus the shear resistance of

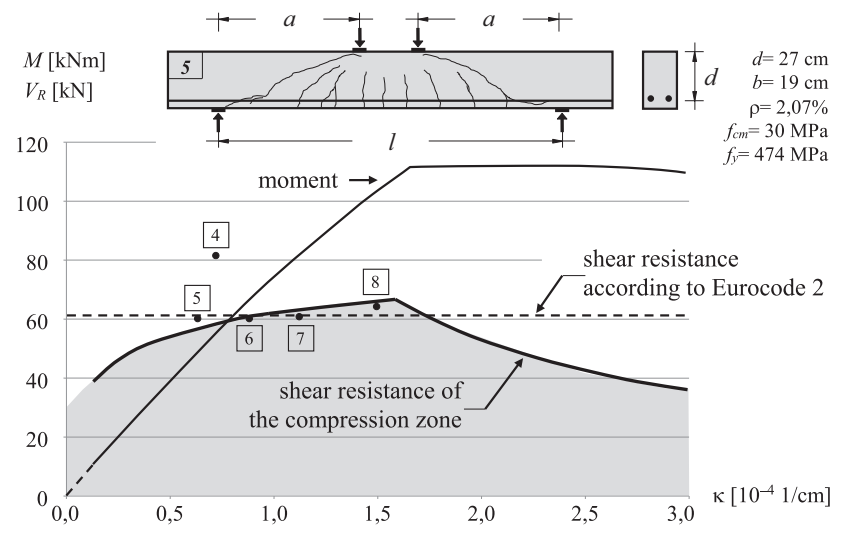

Fig. 6. Moment-curvature and shear resistance-curvature relationships for the cross-section 
the compressive zone is a lower limit value for the shear resistance. For very slender beams, when $a / d$ is greater than 6 , flexural failure occurs prior to the formation of inclined cracks.

\subsection{Estimation for the shear resistance of the compression zone}

As noted previously, the shear resistance of the compressive zone can be calculated as a function of the curvature of the cross-section. Considering the fact that the shear failure occurs at a value less than the flexural moment capacity, and the shear resistance is approximately constant over a wide range, as shown in Fig. 6, a simple expression can be given for estimated shear resistance. If the stress in the extreme compression fibre is $\sigma_{c}=0.60 \ldots 1.00 f_{c m}$, when the shear failure occurs, the shear resistance of a member can be approximately expressed as

$$
V_{R c}=\overline{\tau_{c}} x_{I I} b
$$

where $\overline{\tau_{c}}$ is the average shear stress in the compression zone. Considering the parabolic distribution of shear stresses, the average shear is $\overline{\tau_{c}}=2 / 3 \tau_{c, M O H R}$, in which $\tau_{c, M O H R}=0.5 \sqrt{f_{c m} f_{c t m}}$.

\subsection{The relationship between the shear resistance of the compression zone and the shear resistance according to Eurocode 2}

For further investigation, let us examine Eq. (11). Substituting $\overline{\tau_{c}}=2 / 3 \quad \tau_{c, M O H R}$ and $x_{I I} / d$ into Eq. (11), we obtain

$$
V_{R c}=2 / 3 \tau_{c, M O H R} \frac{x_{I I}}{d} b d
$$

Introducing the notation

$$
v_{R c, M O H R}=2 / 3 \tau_{c, M O H R} \frac{x_{I I}}{d}
$$

Eq. (12) can be written in the following form:

$$
V_{R c}=v_{R c, M O H R} b d
$$

where $v_{R c, M O H R}$ is the characteristic value of shear strength of a reinforced concrete cross-section. However, $v_{R c, M O H R}$ is not empirically derived from test results, as it is based on accurate mechanics of reinforced concrete principles. The value of $v_{R c, M O H R}$ depends on the mean value of concrete compressive strength, $f_{c m}$, the reinforcement ratio for longitudinal reinforcement, $\rho_{l}$, and it can be well approximated by a cube root function.

The approximation was performed in the range of $\rho_{l}=0.1 \ldots 3.0 \%$ by using values of material strength and cross-section parameters of test data reported by Leonhardt and Walther [16]. In these calculations, the concrete strength and the modulus of elasticity of steel were $f_{c m}=30 \mathrm{MPa}$ and $E_{s}=200 \mathrm{GPa}$, respectively. Using $f_{c m}$, the modulus of elasticity of concrete according to Eurocode 2 can be calculated as $E_{c m}=22\left(f_{c m} / 10\right)^{0.3}$. The function of $v_{R c, M O H R}$ and its approximation are shown in Fig. 7.

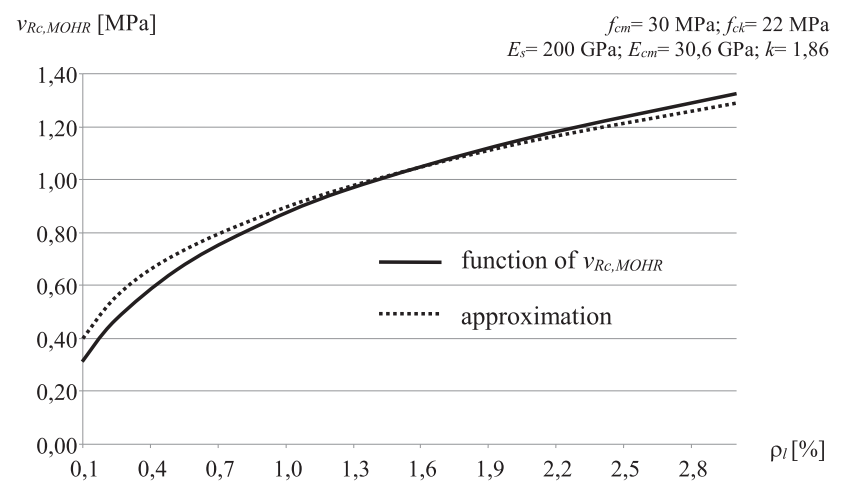

Fig. 7. Function of $v_{R c, M O H R}$ and its approximation in the range of $\rho_{l}=0.1 \ldots .3 .0 \%$

The approximation function for $v_{R c, M O H R}$ was determined by the method of least squares and it can be expressed as

$$
v_{R c, M O H R} \cong 1.44\left(\rho_{l} f_{c k}\right)^{1 / 3}
$$

Substituting this result into Eq. (13), the expression for $V_{R c}$ can be rearranged to

$$
V_{R c}=0.31\left(100 \rho_{l} f_{c k}\right)^{1 / 3} b d
$$

Using the factor $k$ according to Eq. (2) and, after substituting numerical value of $k$, we find that the shear resistance is

$$
V_{R c}=0.17 k\left(100 \rho_{l} f_{c k}\right)^{1 / 3} b d
$$

Comparing this expression with Eq. (4) it can be seen that the formulas are practically the same in case of rectangular cross-section.

Finally, it can be concluded that the shear resistance of a member without shear reinforcement according to Eurocode 2 is the shear resistance of the compression zone of a cracked beam [18]. However, from this it can be concluded that the minimum value of the shear resistance given by Eq. (1.b) should be also related to the compression zone of a cracked beam. This resistance, hereinafter referred to as $V_{R d, c, m i n}$, is considered as the minimum of the shear resistance of a beam. Since the depth of the compression zone is the function of the longitudinal-reinforcement ratio, thus its value can be calculated in case when the required minimum reinforcement ratio is used.

Considering that for the required minimum reinforcement ratio the flexural failure is characteristic, the experimental investigations in this range are very rare. Thus, it is very difficult to verify the prediction of Eurocode 2 for $V_{R d, c, m i n}$. Valuable conclusion can be drawn on this issue, when the steel bars are replaced by glass fibre reinforced polymer bars. Since the modulus of elasticity of the GFRP bars, $E_{G F R P}$, is one fifth of the steel modulus, $E_{s}$, thus in the elastic range of behaviour the GFRP reinforced beam behaves as a steel reinforced beam having an effective reinforcement ratio, $\rho_{l, \text { eff. }}$ The effective 
reinforcement ratio for longitudinal reinforcement can be expressed as

$$
\rho_{l, e f f}=\rho_{l} \frac{E_{G F R P}}{E_{s}}
$$

In this regard, Deitz [19] made important investigations, due to the fact that in his experiments the value of $\rho_{l, e f f}$ was $0.147 \%$, which deviated only by 10 percent from the required minimum reinforcement ratio. For the value of shear span-to-depth a/d $=5.80$, the mean value of the experimental results was $V_{u}=26.81 \mathrm{kN}$ and the estimated value according to Eurocode 2 for the shear resistance is $V_{R c}$ $=38.01 \mathrm{kN}$. When comparing these values, it can be concluded that the Eurocode 2 overestimates the value of $V_{R d, c, \min }$. Considering that the ratio of $V_{u} / V_{R c}$ is 0.705 , instead of Eq. (1.b) the following expression can be proposed

$$
V_{R d, c, \min }=\frac{0.7}{\gamma_{c}} v_{\min } b_{w} d
$$

Based on the model, it is also obvious, that the factor $k$ according to Eurocode 2 describes the changes of the shear strength of concrete as a function of the size of the compression zone. Thus, it is completely analogous to the factor used to convert the compression strength of a nonstandard sized test specimen into characteristic compressive cylinder strength.

\section{THE ERROR OF THE CALCULATED VALUE FOR THE SHEAR RESISTANCE ACCORDING TO EUROCODE 2}

\subsection{The mechanical explanation of the error and determining the range of error}

As discussed previously, the shear failure is well characterized by the shear resistance of the compression zone. Under certain assumptions, the expression of the shear resistance given by Eurocode 2 can be derived. The assumption was that, when the shear failure occurs, the stress in the extreme compression fibre is $\sigma_{c}=0.60 \ldots 1.00 f_{c m}$. In cases when the assumption for the compression zone is not fulfilled, the prediction for the shear resistance according to Eurocode 2 overestimates the value of shear resistance, since in cases when $\sigma_{c}<0.60 f_{c m}$, the shear resistance of the compression zone drops very significantly, as shown in Fig. 6.

Although the low values of mechanical reinforcement ratio also suggest the error of the prediction and could determine the range of error, it is more adequate to determine the value of $\alpha$, which is defined as

$$
\alpha=0.60 \frac{\sigma_{c}^{\prime}}{f_{c m}}
$$

where $\sigma_{c}^{\prime}$ is a fictitious elastic stress in the extreme compression fibre, calculated by assuming that the tension steel is yielding. Thus, $\sigma_{c}^{\prime}$ can be expressed as

$$
\sigma_{c}^{\prime}=\frac{2 A_{s} f_{y}}{b x_{I I}} \text { or } \sigma_{c}^{\prime}=\frac{2 \rho_{l} f_{y}}{\xi_{I I}}
$$

If the value of $\alpha$ is less than 0.60 , then the shear resistance according to Eurocode 2 is overestimated, so the shear resistance can be safely determined by using the improved formula for the minimum value of the shear resistance given by Eq. (18).

To obtain a better estimation for the shear resistance in cases when $\sigma_{c}<0.60 f_{c m}$, let us also determine the value of $\alpha_{\text {min }}$, which can be expressed as

$$
\alpha_{\min }=\frac{\sigma_{c, \min }^{\prime}}{f_{c m}}
$$

where $\alpha_{\text {min }}$ and $\sigma_{c, \text { min }}^{\prime}$ represent the shear failure in the case when the required minimum reinforcement ratio is used, and the subscript $\min$ refers to this case. The calculation for $\sigma_{c \text {,min }}^{\prime}$ is carried out in the similar manner as for $\sigma_{c}^{\prime}$, thus it can be written as

$$
\sigma_{c, \text { min }}^{\prime}=\frac{2 A_{s, \text { min }} f_{y}}{b x_{I I, \min }} \text { or } \sigma_{c, \text { min }}^{\prime}=\frac{2 \rho_{l, \min } f_{y}}{\xi_{I, \text { min }}}
$$

In the following part of the calculation, the characteristic value of shear resistance in cases when $\alpha \geq 0.60$ and in the case when $\alpha=\alpha_{\text {min }}$ are denoted as $V_{R c \text {,max }}$ and $V_{R c, \text { min }}$, respectively. The value of $V_{R c, \text { max }}$ can be calculated using Eq. (4), and the value of $V_{R c, \text { min }}$ can be computed by multiplying the value given by Eq. (18) with the partial factor for concrete, $\gamma_{c}$. Finally, in the case when $\alpha_{\text {min }}<\alpha<0.60$, the modified characteristic value of the shear resistance, $V_{m R c}$, can be calculated by interpolation with the following formula:

$$
V_{m R c}=V_{R c, \min }+\frac{\alpha-\alpha_{\min }}{0.6-\alpha_{\min }}\left(V_{R c, \max }-V_{R c, \min }\right)
$$

Knowing the characteristic value of the shear resistance, the design value of the shear resistance can be calculated by dividing $\gamma_{c}$.

Considering that the condition for the extreme compression fibre, $\sigma_{c}=0.60 \ldots 1.00 f_{c m}$, is typically not fulfilled in case of large, lightly reinforced, high-strength concrete beams, further experimental investigations should focus on these cases.

\subsection{Experiments using large, lightly reinforced concrete beams}

In this subsection, the prediction of the shear resistance is given by Eq. (23) will be compared with the experimental results reported by Collins and Kuchma [20]. From this experimental investigation those non-prestressed simple span beams were selected, which contained neither stirrups nor compression reinforcement. The experimental layout and the details of the test specimens are shown in Fig. 8.

The details of specimens included in the analysis are provided in Table 1. This table also contains the experimental results, $V_{\text {exp. }}$, and the estimation of shear resistance according to Eurocode 2. The shear resistance according to 


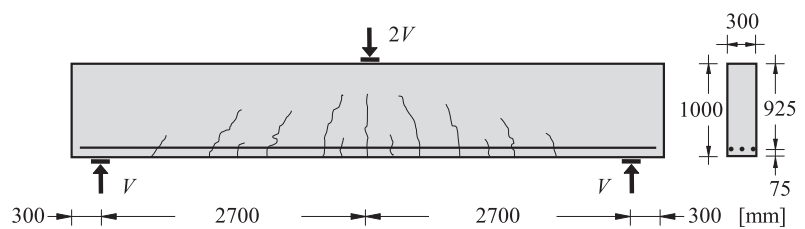

Span dimensions for 50,25 and 12,5 series beams are $50 \%, 25 \%$ and $12,5 \%$ of those above.

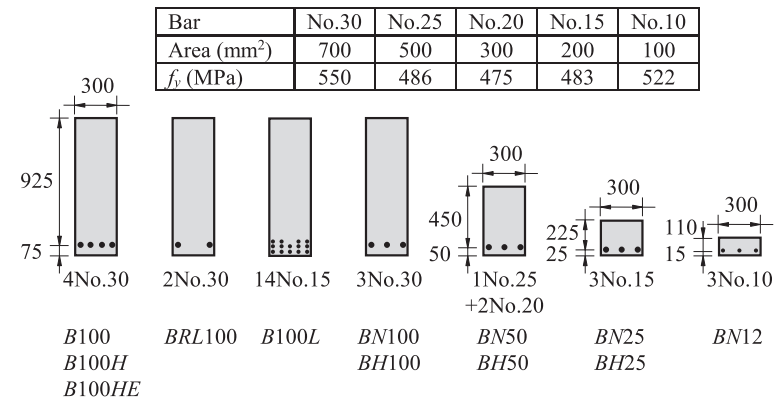

Fig. 8. Details of the selected 12 simple span beams from tests by Collins and Kuchma
Eurocode 2, $V_{R c}$ and $V_{R c, \text { min }}$, were computed by multiplying $\gamma_{c}$ by the values given by Eq. (1.a) and Eq. (18), respectively. The mean value of the concrete cylinder, $f_{c m}$, is calculated with ACI Code [21], using $f_{c m}=1.1 f_{c}^{\prime}+5(\mathrm{MPa})$.

The calculated values are tabulated in Table 2, where the values of $E_{c t m}, f_{c t m}$ and $\rho_{l, m i n}$ are computed according to Eurocode 2. In these tables the high-strength concrete beams are marked by italic-type lettering. The marked cases in Table 1 clearly stand out from the others, and because the ratio of $V_{\text {exp }} / V_{R c}$ are much larger than 1.0, it is clearly visible that the predictions of Eurocode 2 for lightly reinforced high-strength concrete beams are overestimated. It is also striking that for overestimated cases the values of $\alpha$ are very low, as shown in Table 2.

The predictions for the shear resistance by using Eq. (23), $V_{m R c}$, and the ratios of $V_{\text {exp }} / V_{m R c}$ are listed in last two columns of Table 2. From these results it can be concluded that the suggested modified method of calculation for shear resistance results in a more consistent level of safety.

Table 1. Summary of the experimental program, results and predictions

\begin{tabular}{|c|c|c|c|c|c|c|c|c|c|c|c|}
\hline Test specimens & $\begin{array}{c}h \\
\mathrm{~mm}\end{array}$ & $\begin{array}{c}b_{w} \\
\mathrm{~mm}\end{array}$ & $\begin{array}{c}d \\
\mathrm{~mm}\end{array}$ & $f_{c}^{\prime} \mathrm{MPa}$ & $f_{c m} \mathrm{MPa}$ & $\begin{array}{l}\rho_{l} \\
\%\end{array}$ & $f_{y} \mathrm{MPa}$ & $V_{\text {exp }} \mathrm{kN}$ & $V_{R c} \mathrm{kN}$ & $V_{R c, \text { min }} \mathrm{kN}$ & $V_{\text {exp }} / V_{R c}$ \\
\hline$B 100$ & 1,000 & 300 & 925 & 36 & 42.40 & 1.01 & 550 & 225 & 239 & 101 & 1.06 \\
\hline B100HE & 1,000 & 300 & 925 & 98 & 104.4 & 1.01 & 550 & 217 & 337 & 169 & 1.55 \\
\hline$B 100 L$ & 1,000 & 300 & 925 & 39 & 45.40 & 1.01 & 483 & 223 & 246 & 105 & 1.10 \\
\hline$B N 100$ & 1,000 & 300 & 925 & 37.2 & 43.60 & 0.76 & 550 & 192 & 220 & 103 & 1.14 \\
\hline$B N 25$ & 250 & 300 & 225 & 37.2 & 43.60 & 0.89 & 483 & 73 & 75 & 38 & 1.02 \\
\hline$B N 12$ & 125 & 300 & 110 & 37.2 & 43.60 & 0.91 & 522 & 40 & 38 & 19 & 0.95 \\
\hline BH100 & 1,000 & 300 & 925 & 98.8 & 105.2 & 0.76 & 550 & 193 & 307 & 150 & 1.59 \\
\hline BH50 & 500 & 300 & 450 & 98.8 & 105.2 & 0.81 & 486 & 132 & 174 & 100 & 1.32 \\
\hline BH25 & 250 & 300 & 225 & 98.8 & 105.2 & 0.89 & 483 & 85 & 104 & 63 & 1.23 \\
\hline BRL100 & 1,000 & 300 & 925 & 94 & 100.4 & 0.50 & 550 & 163 & 263 & 165 & 1.61 \\
\hline
\end{tabular}

Table 2. Summary of the calculated values and predictions by using Eq. (23)

\begin{tabular}{lccccccccccc}
\hline Test specimens & $E_{c m} \mathrm{GPa}$ & $f_{c t m} \mathrm{MPa}$ & $\xi_{I I}$ & $\sigma_{c}^{\prime} \mathrm{MPa}$ & $\alpha$ & $\begin{array}{c}\rho_{l, m i n} \\
\%\end{array}$ & $\xi_{I I, \text { min }}$ & $\sigma_{c, \text { min }}^{\prime} \mathrm{MPa}$ & $\alpha_{\text {min }}$ & $V_{m R c} \mathrm{kN}$ & $V_{\text {exp }} / V_{m R c}$ \\
\hline B100 & 34.45 & 3.31 & 0.291 & 38.23 & 0.514 & 0.156 & 0.126 & 13.65 & 0.306 & 200.2 & 0.89 \\
B100H & 45.51 & 5.32 & 0.259 & 42.84 & 0.228 & 0.251 & 0.138 & 20.04 & 0.178 & 196.7 & 1.02 \\
B100HE & 45.51 & 5.32 & 0.259 & 42.84 & 0.228 & 0.251 & 0.138 & 20.04 & 0.178 & 196.7 & 0.91 \\
B100L & 35.20 & 3.50 & 0.288 & 33.86 & 0.424 & 0.189 & 0.136 & 13.39 & 0.279 & 171.5 & 0.77 \\
BN100 & 34.76 & 3.39 & 0.257 & 32.53 & 0.425 & 0.160 & 0.127 & 13.88 & 0.302 & 153.9 & 0.80 \\
BN50 & 34.76 & 3.39 & 0.264 & 29.82 & 0.390 & 0.181 & 0.134 & 13.11 & 0.285 & 83.75 & 0.63 \\
BN25 & 34.76 & 3.39 & 0.275 & 31.30 & 0.409 & 0.182 & 0.135 & 13.07 & 0.285 & 53.62 & 0.73 \\
BN12 & 34.76 & 3.39 & 0.277 & 34.26 & 0.448 & 0.169 & 0.130 & 13.55 & 0.295 & 29.10 & 0.73 \\
BH100 & 45.62 & 5.33 & 0.229 & 36.46 & 0.192 & 0.252 & 0.138 & 20.09 & 0.177 & 163.1 & 0.84 \\
BH50 & 45.62 & 5.33 & 0.236 & 33.39 & 0.176 & 0.285 & 0.146 & 18.97 & 0.167 & 106.5 & 0.81 \\
BH25 & 45.62 & 5.33 & 0.245 & 35.04 & 0.185 & 0.287 & 0.147 & 18.92 & 0.166 & 68.12 & 0.80 \\
BRL100 & 44.97 & 5.24 & 0.192 & 28.68 & 0.159 & 0.248 & 0.138 & 19.77 & 0.182 & 168.6 & 1.03 \\
\hline
\end{tabular}




\section{CONCLUSIONS}

The final results of the analysis show that the initial assumption was correct, thus the shear resistance of a beam without stirrups is well characterized by the shear resistance of the compression zone. Furthermore, the expression of the shear resistance given by Eurocode 2, under certain assumptions, can be derived.

Knowing the mechanical background of the empirical expressions of Eurocode 2, it can be shown, that if the stress in the extreme compression fibre is less than $0,60 f_{c m}$ when the shear failure occurs, the prediction for the shear resistance according to Eurocode 2 overestimates the value of shear resistance. Thus, in these cases, the predictions for the shear resistance should be corrected, for those of which the procedure is presented in detail in Section 5.1. After comparison of the corrected values for the shear resistance with experimental results reported by Collins and Kuchma, where the shear resistance according to Eurocode 2 is overestimated, it can be concluded that the suggested modified method of calculation for shear resistance results in a more consistent level of safety.

During the analysis, it was possible to demonstrate that the lower bound value of the shear resistance according to Eurocode 2 given by Eq. (1.b), overestimates the value of shear resistance. Thus, it is recommended to change the minimum value of shear resistance, as given in Eq. (18).

\section{ACKNOWLEDGEMENT}

The author of this paper would like to express his special thanks to Professor István Hegedüs, who was the supervisor of the $\mathrm{PhD}$ research related to this paper, for his valuable advice, constant guidance, and encouragement during every stage of the research.

\section{REFERENCES}

[1] J. K. Wight, and J. G. MacGregor, Reinforced Concrete: Mechanics and Design. Pearson, 2016.

[2] P. A. Clark, "Diagonal tension in reinforced concrete beams," ACI J. Proc., vol. 48, no. 10, pp. 145-56, 1951.

[3] J-Y. Lee, and U-Y. Kim, "Effect of longitudinal tensile reinforcement ratio and shear span-depth ratio on minimum shear reinforcement in beams," ACI Struct. J., vol. 105, no. 2, pp. 134-44, 2008.
[4] B. Hu, and Y-F. Wu, "Effect of shear span-to-depth ratio on shear strength components of RC beams," Eng. Struct., vol. 168, pp. 770-83, 2018.

[5] G. N. J. Kani, "How safe our large reinforced concrete beams?" ACI J. Proc., vol. 64, no. 3, pp. 128-41, 1967.

[6] Z. P. Bazant, and J-K. Kim, "Size effect in shear failure of longitudinally reinforced beams," ACI J. Proc., vol. 81, no. 5, pp. 456-68, 1984.

[7] H. P. J. Taylor, Investigation of Forces Carried across Cracks in Reinforced Concrete Beams in Shear by Interlock of Aggregate, London: Cement and Concrete Association, 1970, Technical Report 42.

[8] J. C. Walraven, "Fundamental analysis of aggregate interlock," ASCE J. Struct. Div., vol. 107, no. 11, pp. 2245-70, 1981.

[9] MSZ EN 1992-1-1:2010 Eurocode 2, Betonszerkezetek Tervezése, 1-1. Rész: Általános És Az Épületekre Vonatkozó Szabályok, Európai Szabvány, 2010.

[10] L. P. Kollár, and I. Vasbetonszerkezetek, Vasbeton-szilárdságtan Az Eurocode 2 Szerint, Budapest: Múegyetemi Kiadó, 1999.

[11] I. Völgyi, and A. Windisch, "Experimental investigation of the role of aggregate interlock in the shear resistance of reinforced concrete beams," Struct. Concrete, vol. 18, no. 5, pp. 792-800, 2017.

[12] B. Bogdándy, Átszúródásra Vasalatlan Vasbeton Lemezek Átszúródási Teherbírása, $\mathrm{PhD}$ értekezés, 2016.

[13] R. Walther, "Über die Berechnung der Schubtragfähigkeit von Stahl- und Spannbetonbalken," Schubbruchtheorie, Beton- und Stahlbetonbau, pp. 261-71, 1962/11.

[14] T. Kármán, A Hajlitott Vasbetontartó Nyomott-Nyirt Zónájának Teherbírásával Kapcsolatos Kísérletek, ÉTI Tudományos Közlemények, pp. 25-42, 1967.

[15] Fib Bulletin 12, Lausanne: Punching of Structural Concrete Slabs, 2001.

[16] F. Leonhardt, and R. Walther, Beiträge zur Behandlung der im Stahlbetonbau, Beton- und Stahlbetonbau, pp. 32-44, 1962/2.

[17] A. K. Tureyen, and R. J. Frosch, "Concrete shear strength: another perspective," ACI Struct. J., vol. 100, no. 5, pp. 609-15, 2003.

[18] B. Bogdándy, and I. Hegedüs, "A nyomott öv nyírási teherbírása és az Eurocode szerinti nyírási ellenállás kapcsolata," Vasbetonépités, pp. $62-7,2014 / 3$.

[19] D. Deitz, GFRP Reinforced Concrete Bridge Decks, PhD Dissertation, Lexington, Ky: School of Civil Engineering, University of Kentucky, 1998.

[20] M. P. Collins, and D. Kuchma, "How safe our large, lightly reinforced concrete beams, slabs, and footings?," ACI Struct. J., vol. 96, no. 4, pp. 482-90, 1999.

[21] ACI 302M-05, Specifications for Structural Concrete, Reported by ACI Committee 301, 2005. 